\title{
AVALIAÇÃo TÉCNICA E PEDAGÓGICA DO JOGO SÉRIO “JOY E AS LETRINHAS"
}

\author{
Mateus José de Faria, Faculdade de Tecnologia de Mococa - FATEC, \\ mateus034@hotmail.com \\ Rogério Colpani, Faculdade de Tecnologia de Mococa - FATEC, \\ rocolpani@gmail.com
}

Resumo: Os métodos tradicionais de ensino, focados no giz e quadro negro, cada vez mais dão lugar às inovações e novas tecnologias, como os jogos eletrônicos educativos. O presente artigo apresenta uma proposta de utilização de um Jogo Sério, batizado de "Joy e as Letrinhas", para auxílio no processo de ensino/aprendizagem da alfabetização de crianças. De forma a avaliar a qualidade do Jogo Sério, o mesmo passou por uma avaliação qualitativa realizada por uma equipe multidisciplinar utilizando uma adaptação da avaliação LORI, a fim de se ter opiniões quanto a facilidade de aprendizagem e utilização. Como resultado, este Jogo Sério pode ser empregado em inúmeros contextos e níveis de aprendizagem, contribuindo para a evolução na alfabetização de crianças, proporcionando motivação e interesse no aprendizado.

Palavras-chave: Jogos Sérios, Ensino/Aprendizagem, Alfabetização

\section{TECHNICAL AND PEDAGOGICAL EVALUATION OF SERIOUS GAME "JOY E AS LETRINHAS"}

\begin{abstract}
Traditional teaching methods, focused on chalk and blackboard, increasingly give way to innovations and new technologies, such as educational electronic games. This article presents a proposal to use a Serious Game, called "Joy e as Letrinhas", to aid in the process of teaching/learning children's literacy. In order to evaluate the quality of the Serious Game, it has undergone a qualitative evaluation carried out by a multidisciplinary team using an adaptation of the LORI evaluation, in order to have opinions about the ease of learning and use. As a result, this Serious Game can be used in numerous contexts and levels of learning, contributing to the evolution in children's literacy, providing motivation and interest in learning.
\end{abstract}

Keywords: Serious Games, Teaching/Learning, Literacy

\section{INTRODUÇÃO}

Durante muitos anos, os alunos eram vistos como seres passivos da aprendizagem, cabendo ao professor transmitir seus conhecimentos de forma verticalizada. Com as seguidas mudanças sofridas pela sociedade, foi imprescindível o surgimento de novos modelos e métodos de ensino, capazes de conduzir aos alunos maiores desafios e que considerassem seus conhecimentos prévios estabelecidos (LIMA et. al., 2009).

Neste sentido, surge a importância de fazer da educação algo maior do que uma simples transferência de informações, algo que transcenda os limites da repetição e memorização, que leve o aluno a fazer a diferença no meio em que vive, independentemente das condições que este meio oferece (DUDEK e COSTA, 2012).

Existem inúmeros métodos de ensino capazes de transcender o tradicionalismo. Estes métodos possuem informações que favorecem a comunicação e o aprendizado, 
possibilitando amplas mudanças que, em muitos casos, são absolutamente necessários para satisfazer certos objetivos (SILVA, 2011).

Dentre os inúmeros métodos de ensino é válido destacar os jogos educativos. Segundo Souza (2013), os jogos educativos auxiliam o desenvolvimento da motricidade, da linguagem, da memória, da percepção e da apropriação dos signos. A presença dos jogos, na vida do aluno, é fundamental para o seu desenvolvimento, tornando seu aprendizado dinâmico, atrativo, possibilitando a ampliação de conhecimentos e facilitando o processo de ensino/aprendizagem.

Por esta ótica, destacam-se os jogos educativos eletrônicos, os quais são compreendidos como ambientes interativos que, ao oferecer desafios, capturam a atenção do jogador. Segundo Magagnin e Toschi (2009), jogos deste tipo podem contribuir significativamente com o desenvolvimento da criatividade do aluno, auxiliando-o em tomadas de decisão, estimulando sua iniciativa e autoconfiança ao mesmo tempo que aperfeiçoa sua linguagem e pensamento.

Neste contexto, uma das ferramentas que pode ajudar a motivar e ser utilizada em sala de aula são os Jogos Sérios. Estes recursos didáticos têm se destacado nos últimos anos, enriquecendo as aulas, fazendo-as dinâmicas e motivadoras, contribuindo para a qualidade do ensino e reforçando conceitos (KARLINI, RIGO, 2014).

Com base no exposto, esta pesquisa tem como objetivo apresentar o Jogo Sério "Joy e as Letrinhas" e avaliá-lo de forma a verificar sua qualidade e absorver possíveis feedbacks para a melhoria deste.

O artigo está estruturado em seis seções. Na primeira seção é feita a introdução ao tema, expondo a necessidade do surgimento de novos métodos de ensino e evidenciando os jogos educativos. A segunda seção apresenta uma breve contextualização sobre os Jogos Sérios e sua contribuição na educação. A terceira seção abordará as ferramentas utilizadas no desenvolvimento do Jogo Sério e a descrição das atividades realizadas no mesmo. A quarta seção abordará o protocolo de avaliação LORI e sua coleta de dados. Na quinta seção será apresentada a análise dos resultados da pesquisa em questão. Por fim, a sexta seção apresenta as considerações finais.

\section{JOGOS SÉRIOS}

Atualmente, a sociedade vem experimentando uma categoria peculiar de jogos eletrônicos desenvolvidos para abordar aspectos que transcendem o entretenimento, esta categoria é denominada Jogos Sérios. Segundo Machado e Valença (2011), Jogos Sérios podem ser definidos como jogos virtuais que possibilitam a simulação de situações críticas ou práticas, proporcionando o treinamento profissional, a conscientização de crianças, jovens e adultos ou mesmo auxiliar em situações corriqueiras.

Uma das primeiras menções deste termo na literatura encontra-se no livro "Serious Games" escrito por Clark C. Abt em 1970. Este autor foi membro de um laboratório de pesquisas norte americano durante a guerra fria. Um de seus objetivos foi utilizar jogos em treinamentos militares e na educação. Com este intuito, Abt desenvolveu inúmeros Jogos Sérios, dentre eles o T.E.M.P.E.R. (Technological Economic Military Political Evaluation Routine), primeiro modelo matemático interdisciplinar do departamento de defesa americano para estudo da guerra fria e seu contexto (GOULD, BARKUN, 2015).

O diferencial apresentado pelos Jogos Sérios em relação a outros tipos de jogos é o foco em resultados de aprendizagem específica e intencional. Oliveira et. al. (2014), observa que estes jogos são abordagens promissoras tanto a nível econômico quanto a nível de resultados obtidos. 


\subsection{Jogos Sérios na educação}

Jogos Sérios encaixam-se perfeitamente às estratégias educacionais, visto que eles propiciam aos alunos uma nova visão aos conteúdos ministrados em sala de aula. Esta estratégia pode ser validada por intermédio de testes aplicados antes e depois do uso dos jogos (SILVA, MORAIS, 2011).

Os Jogos Sérios podem ser de utilidade fundamental à educação, pois oferecem ambientes imersivos e envolventes, onde os alunos podem aprender por intermédio da tentativa e erro. Este tipo de abordagem desenvolve o trabalho de equipe entre os alunos em sala de aula, além das competências pessoais, liderança e a colaboração mutua (CARVALHO, ANDRÉS, ARBELOA, 2012).

Conforme destacam Savi e Ulbricht (2008), os Jogos Sérios podem oferecer alguns benefícios à aprendizagem como efeito motivador, facilidade de aprendizagem, aprendizagem por descoberta e socialização.

Monteiro, Magagnin e Araújo (2009), salientam que os Jogos Sérios contribuem, ainda, com o desenvolvimento da criatividade, na tomada de decisões, auxilia o aluno a refletir e a fazer descobertas ao transportar diversas situações que poderiam ser vivenciadas no mundo real. Por meio destes jogos, o aluno aprimora a iniciativa, a autoconfiança, a linguagem, o pensamento e a concentração. Desta maneira, os Jogos Sérios podem desenvolver as diversas capacidades intelectuais do aluno.

No Brasil, o MEC (Ministério da Educação) instiga educadores e alunos a utilizarem a "Britannica Escolar Online", uma plataforma de aprendizagem online cujo objetivo é disponibilizar materiais didáticos para o enriquecimento do processo de aprendizagem através de jogos interativos, pesquisas, vídeos, mapas, notícias e entre outros. Os educadores podem desenvolver seus planos de aula e realizar pesquisas utilizando o sistema de busca por assunto (ATAIDE, 2012).

Com base no exposto, os Jogos Sérios mostram-se capazes de auxiliar crianças no processo de ensino/aprendizagem, proporcionando conhecimento e auxiliando-as na aprendizagem de diversos conteúdos.

\section{JOY E AS LETRINHAS}

Nesta seção será apresentado o levantamento de requisitos, as ferramentas utilizadas para o desenvolvimento e edição de imagens e a descrição do jogo e suas atividades.

\subsection{Levantamento de requisitos e ferramentas utilizadas}

Com o intuito de auxiliar crianças no processo de ensino/aprendizagem da alfabetização, foi desenvolvido um Jogo Sério batizado de "Joy e as Letrinhas" para crianças em processo de alfabetização, com faixa etária entre 6 a 8 anos de idade. Para este desenvolvimento, foi necessário um levantamento de requisitos, o qual foi realizado em uma instituição filantrópica assistencial da cidade de Mococa-SP, chamada Artesanato - Centro de Desenvolvimento Social de Mococa, elaborado e realizado por pedagogas participantes do projeto.

Para o levantamento supracitado, foram levados em conta a idade do público alvo, seu nível alfabético, o conteúdo programático exigido pelo MEC e a experiência das pedagogas. Estes elementos são de suma importância, visto que por meio deles o aprendizado pode manifestar-se de maneira semelhante ou superior aos métodos tradicionais de ensino. 
Para o desenvolvimento do Jogo Sério, foram utilizados dois softwares de edição e vetorização de imagens, sendo o CorelDraw X8 ${ }^{1}$, para criação de personagens, cenários e objetos diversos e o Adobe Photoshop $\mathrm{CC}^{2}$, para ajustes finais nas imagens, edição de cores, luminosidade e entre outras funções.

O motor de jogo escolhido para o desenvolvimento foi o Construct $2^{3}$. Este motor possui um sistema de "arraste e solte" (drag-and-drop) e fornece uma série de scripts que facilita sua programação. Este motor tem como foco a criação de jogos em duas dimensões (2D), sendo dotado de recursos e sistemas de física, de áudio e de gráficos.

\subsection{Descrição do Jogo Sério}

O Jogo Sério "Joy e as Letrinhas" possui, como personagem principal, o "Professor Joy" e uma tutora chamada "Professora Angélica". Na medida em que o personagem principal avança pelas fases, sua tutora explica detalhadamente como proceder em cada uma das atividades. Cada atividade contida no jogo apresenta um tema diferente, de forma a estimular a imaginação das crianças. Todos os conteúdos abordados nas atividades foram preparados de forma a obedecer aos critérios estabelecidos por uma comissão formada por pedagogos e especialistas da área, seguindo um nível de dificuldade determinado e conteúdos que vão desde ordenação de vogais e consoantes até escrita de palavras com letras e sílabas.

O cenário principal, apresentado na Figura 1, contém três botões, "Jogar", "Créditos" e "Sair", que levam o jogador ao início das atividades, aos participantes do desenvolvimento do Jogo Sério e ao encerramento do jogo respectivamente. Ao clicar em "Jogar", o jogador é enviado ao próximo cenário, onde se encontra a tela de escolha do nome, apresentada na Figura 1. Neste cenário, o jogador poderá escrever seu nome, o qual será exibido em todas as fases ao término das atividades.

$\mathrm{Na}$ tela de seleção de fases, apresentada na Figura 1, são dispostas oito fases, onde apenas a primeira é liberada e as outras sete são desbloqueadas uma a uma. Além da escolha das fases, nesta tela é possível ter acesso ao "Mercado", apresentada na Figura 1, onde o jogador poderá adquirir outros quatro personagens, além do seu personagem principal padrão.
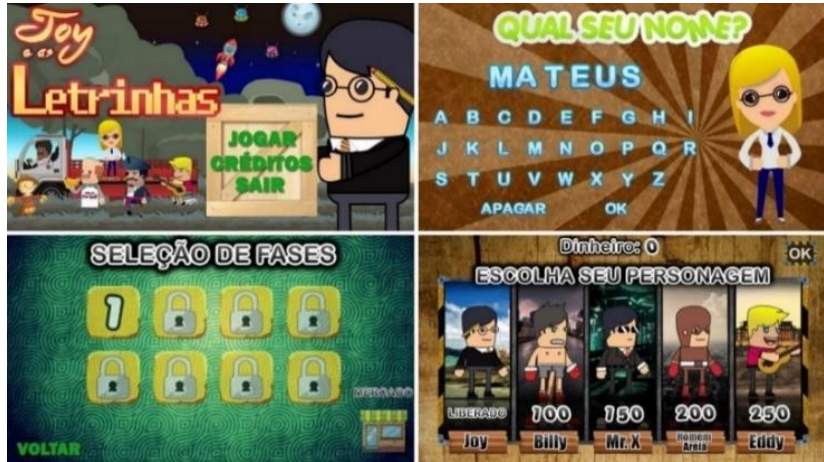

Figura 1: Tela principal, escolha do nome, seleção de fases e mercado (Fonte: Autoria própria, 2017).

Após escolher a primeira fase, o jogador é enviado à minifase "Como Jogar", apresentada na Figura 2. Esta tela é um tutorial que ensina os controles básicos do jogo

\footnotetext{
${ }^{1}$ CorelDraw X7. Disponível em: http://www.coreldraw.com/br/product/graficos-tecnicos/?topNav=br

${ }^{2}$ Adobe Photoshop CC. Disponível em: http://www.adobe.com/br/products/photoshop.html

${ }^{3}$ Construct 2. Disponível em: https://www.scirra.com
} 
por meio de feedbacks de áudio e imagem, criando meios para que o jogador compreenda o que deve ser feito nas próximas fases.

Ao completar a minifase, o jogador é enviado à fase 1, apresentada na Figura 2. Esta fase se passa em uma fábrica, onde o jogador deverá completar o alfabeto com as vogais que faltam. Para auxiliar o jogador, existem feedbacks em áudio e em vídeo, explicando detalhadamente cada passo da atividade. Assim como a fase 1, a fase 2, apresentada na Figura 2, é ambientada na mesma fábrica, onde o jogador deverá completar o alfabeto com as consoantes que faltam. A fase 3, apresentada na Figura 2, tem como tema o circo. Nesta fase, o jogador deverá colocar as vogais na ordem correta.

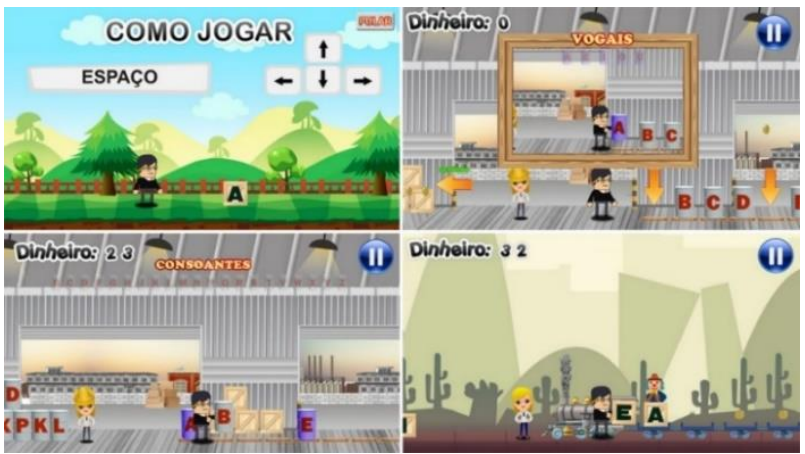

Figura 2: Tela minifase, fase 1 e 2 - Fábrica e fase 3 - Circo (Fonte: Autoria própria, 2017).

Na fase 4, apresentada na Figura 3, o jogador deverá coletar o maior número de vogais possíveis durante três minutos. Ao iniciar a fase, o jogador receberá os feedbacks em áudio e vídeo e, logo, será iniciada a contagem regressiva e o início do jogo. Cada letra correta coletada dará 1 ponto e cada letra incorreta subtrairá 1 ponto. Ao término da fase, o jogador receberá os feedbacks da pontuação.

O próximo cenário é a fase 5, apresentada na Figura 3. Nesta fase, o jogador irá encontrar quatro atividades, onde ele deverá completar as palavras com as vogais que faltam. Na primeira atividade, o jogador deverá completar a palavra "Leite" e, para isso, receberá feedbacks dos personagens que estão a sua volta.

Na próxima atividade, o jogador encontrará um grande palco contendo um músico e uma mocinha, a "Belinha", apresentados na Figura 3. Ao aproximar-se da personagem, o jogador receberá os feedbacks de como completar a atividade, onde o objetivo será completar a palavra "Música" colocando as caixas com vogais nas lacunas correspondentes.

A terceira atividade, apresentada na Figura 3, levará o jogador até a quitanda do "Seu Nenê", onde ele deverá completar a palavra "Feira". A cada letra completada, o personagem dará feedbacks positivos, assim como ao completar a palavra.

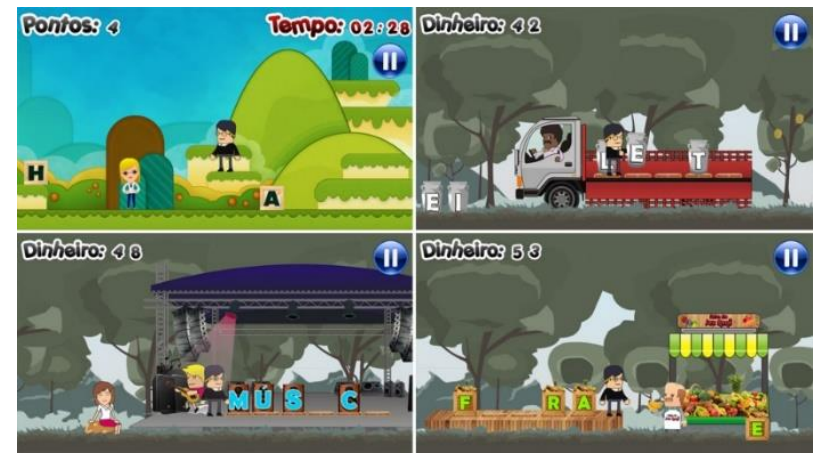

Figura 3: Fase 4 - Coleta de letras e fase 5 - Leite, Música e Feira (Fonte: Autoria própria, 2017). 
$\mathrm{Na}$ última atividade, o jogador chegará ao mar e encontrará o "Pirata", apresentados na Figura 4. O jogador, ao aproximar-se do pirata, receberá feedbacks em áudio e vídeo, os quais irão lhe auxiliar no complemento da palavra "Tesouro", utilizando baús com vogais. Cada letra completada com sucesso dará um feedback e, ao terminar todas as atividades, o jogador receberá o feedback final da "Professora Angélica", assim como a palavra "Parabéns" e o nome do jogador fixados na tela.

A fase 6, apresentada na Figura 4, levará o jogador até o espaço. Esta fase é uma roupagem do saudoso jogo Space Invaders. Existem diversas naves alienígenas lançando asteroides contendo vogais e consoantes, onde o objetivo é coletar cinco vogais de cada, evitando ser atingido pelos asteroides das consoantes. No início da fase, a agora "Astronauta Angélica", explicará o que deverá ser feito pelo jogador e, ao término, ele receberá feedbacks positivos e terá seu nome fixado na tela.

A fase 7, exibida na Figura 4, se passa em uma bela cidade. Aproximando-se da "Professora Angélica", a mesma explica os objetivos da atividade e como fazê-la. O jogador deverá escrever as palavras referentes às imagens utilizando as caixas com sílabas. Existem diversas sílabas nas caixas e estas estão misturadas entre si, o jogador deverá observar o desenho e colocar as sílabas corretas nos locais indicados, recebendo feedbacks.

O cenário seguinte é a segunda minifase "Como Jogar", descrita na Figura 4. Esta minifase é necessária para que o jogador se ambiente aos novos controles do jogo. Desta vez, o jogador deverá utilizar o mouse para puxar o personagem e soltá-lo, arremessandoo em direção a um alvo.

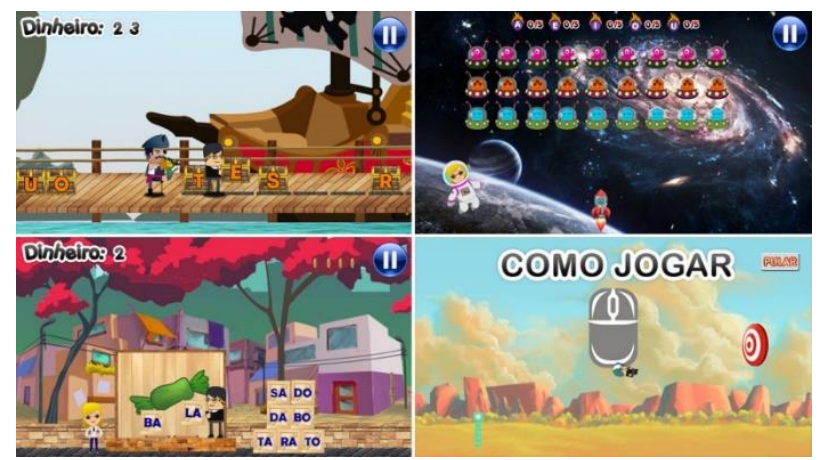

Figura 4: Fase 5 - Palavra: Tesouro, fase 6 - Coleta de vogais, fase 7 - Sílabas e Minifase - Como jogar (Fonte: Autoria própria, 2017).

A oitava e última fase, apresentada na Figura 5, se passa em uma casa assombrada, na qual existem três imagens distintas e o nome de uma delas fixo na tela. O jogador deve ler a palavra, clicar no personagem, arrastar o mouse, mirar na imagem correta e soltar. Ao acertar a imagem correta, ela desaparecerá, a "Bruxinha Angélica" dirá o nome da imagem e o personagem retornará ao ponto inicial para ser lançado novamente. Ao todo, são nove imagens diferentes a serem atingidas pelo jogador que, ao atingi-las, receberá feedbacks parabenizando-o.

Ao completar todas as fases, o jogador é enviado ao cenário final, apresentado na Figura 5. Este cenário marca o fim do jogo, onde há um feedback parabenizando o jogador pelo término de todas as atividades e tem seu nome fixado na tela. Ao final deste cenário, o jogador é enviado à tela inicial do jogo, onde poderá refazer todas as fases na ordem que bem entender. 


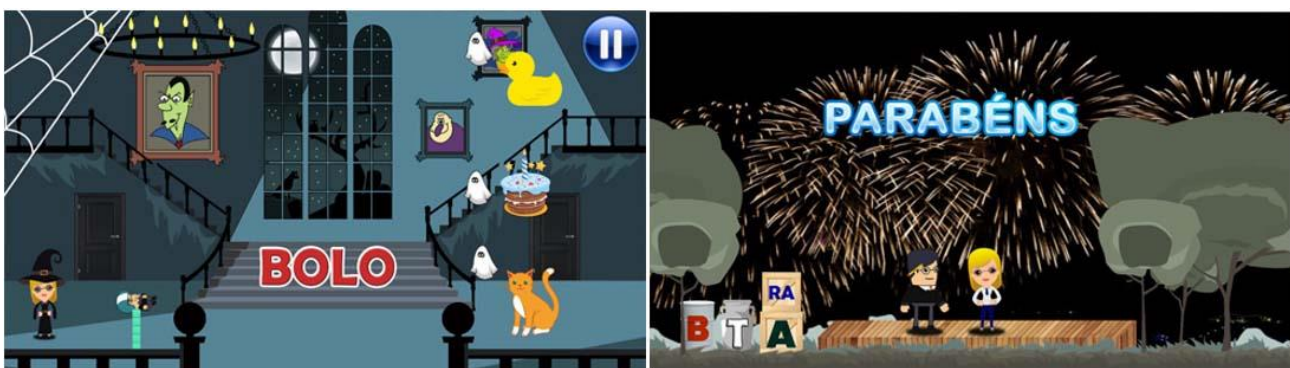

Figura 5: Fase 6 - Casa assombrada e Cenário final (Fonte: Autoria própria, 2017).

Todas as atividades levam, às crianças, momentos de interação e divertimento para que possam compreender a natureza alfabética, estimulando o conhecimento das vogais e consoantes, a memorização das mesmas e identificação das sílabas.

\section{PROTOCOLO DE AVALIAÇÃO}

Nesta seção, serão apresentados os procedimentos utilizados para a realização de uma pesquisa qualitativa, a qual foi feita com o objetivo de avaliar a usabilidade e a interação entre o usuário e o Jogo Sério. Desta maneira, será possível verificar a qualidade deste e absorver possíveis feedbacks, positivos e/ou negativos, para sua melhoria.

A coleta de dados foi efetuada por intermédio de um questionário que compreende um total de 9 critérios, sendo 1 pedagógico, 4 relativos à interface e 4 relativos à qualidade do Jogo Sério. Os critérios foram associados a escala Likert de 5 pontos, com variação entre 1 (um) à 5(cinco).

\subsection{Instrumento de avaliação LORI}

Segundo Alvarez (2014), o instrumento de avaliação LORI (Learning Object Review Instrument) foi desenvolvido no Canadá pela e-Learning Research and Assessment Network (eLera) para a avaliação dos objetos de aprendizagem no âmbito internacional. O LORI é composto por 9 questões utilizadas como parâmetro para analisar os itens relacionados a qualidade do Jogo Sério, porém, para a presente pesquisa, o instrumento de avaliação foi adaptado para o devido contexto. Os itens utilizados para a avaliação são descritos abaixo:

- Qualidade do conteúdo: veracidade, precisão, apresentação equilibrada de ideias e nível de detalhe apropriado.

- Alinhamento de metas de aprendizagem: alinhamento entre objetivos de aprendizagem, atividades, avaliações e características do aluno.

- Feedback e Adaptação: Conteúdo adaptável ou feedback orientado pela entrada diferencial do aprendiz ou modelagem do aprendiz.

- Motivação: Motivar e interessar uma população identificada de alunos.

- Design de apresentação: design de informações visuais e auditivas para melhor aprendizado e processamento mental eficiente.

- Usabilidade de interação: Facilidade de navegação, previsibilidade da interface do usuário e qualidade dos recursos de ajuda da interface.

- Acessibilidade: Acessibilidade a alunos com deficiências.

Cada uma das variáveis do instrumento é avaliada em uma escala Likert de 5 pontos, onde: 1-Ruim, 2-Regular, 3-Bom, 4-Muito Bom e 5-Excelente. Os resultados da avaliação de cada variável são, quase sempre, expressos em valores médios, seguidos de comentários dos avaliadores (NESBIT, BELFER, LEACOCK, 2009). 
Segundo Medeiros e Schimiguel (2012), dentre os itens avaliados, caso haja algum considerado irrelevante para a pesquisa ou o avaliador não se sinta qualificado para julgar tal critério, o item pode ser excluído, aplicando-se a ele o termo "não aplicável".

\subsection{Coleta de dados}

O tipo de amostragem empregada na coleta de dados da pesquisa é caracterizada como não-probabilística, intitulada de amostra intencional. Esta amostra é dotada de indivíduos eleitos propositalmente pelo entrevistador, o qual julga os mesmos como detentores de características típicas ou representativas da população (OLIVEIRA, 2001).

Com base neste contexto, foi escolhida para a coleta de dados da pesquisa, uma equipe multidisciplinar que contou com a participação de uma coordenadora pedagógica, uma psicóloga, uma assistente social e duas pedagogas. Esta equipe faz parte do corpo docente do Artesanato - Centro de Desenvolvimento Social de Mococa, a qual foi possível examinar o Jogo Sério "Joy e as Letrinhas" e o submeter a avaliação.

Por meio desta avaliação, será possível verificar a qualidade e a possibilidade da utilização do Jogo Sério como uma ferramenta no auxílio da alfabetização de crianças.

\section{ANÁLISE DOS RESULTADOS}

O Jogo Sério foi avaliado por uma equipe multidisciplinar dotada de duas pedagogas (P1 e P2), uma assistente social (AS), uma psicóloga (PS) e uma coordenadora pedagógica $(\mathrm{CP})$ que trabalham diretamente com crianças em processo de alfabetização a 3, 4, 28, 3 e 5 anos respectivamente. A média de idade desta equipe é de 34,6 anos, onde as pedagogas P1 e P2 possuem 27 e 26 anos, a assistente social 63 anos, a psicóloga 29 anos e a coordenadora pedagógica 28 anos. O Jogo Sério foi avaliado pela equipe multidisciplinar em uma seção de 40 minutos separadamente.

A Tabela 1 apresenta as notas referentes ao instrumento de avaliação LORI dadas pela equipe multidisciplinar posteriormente à avaliação do Jogo Sério.

Tabela 1 - Notas das seções do questionário.

\begin{tabular}{lcccccc}
\hline \multicolumn{1}{c}{ DIMENSÃO } & P1 & P2 & AS & PS & CP & Média \\
\hline Qualidade do conteúdo & 4 & 5 & 5 & 4 & 4 & 4,4 \\
Alinhamento de metas de aprendizagem & 4 & 4 & 4 & 5 & 4 & 4,2 \\
Feedback e Adaptação & 5 & 4 & 4 & 5 & 5 & 4,6 \\
Motivação & 5 & 4 & 5 & 5 & 5 & 4,8 \\
Design de apresentação & 5 & 4 & 5 & 4 & 5 & 4,6 \\
Usabilidade de interação & 4 & 5 & 4 & 5 & 5 & 4,6 \\
Acessibilidade & 3 & 3 & 3 & 4 & 3 & 3,2 \\
\hline
\end{tabular}

Dentre as dimensões supracitadas na tabela, a equipe multidisciplinar destacou algumas funções que se destacaram no Jogo Sério, como a qualidade do conteúdo, onde pode ser empregado em inúmeros contextos de aprendizagem e adequado a níveis diferentes de alunos. Além disso, o Jogo Sério oferece diversos feedbacks, em áudio e vídeo, auxiliando crianças que ainda não estão totalmente alfabetizadas, criando um ambiente propenso e gerador de conhecimento.

A equipe multidisciplinar também destacou a importância da motivação que o Jogo Sério provoca nos alunos, pois seu conteúdo difere intencionalmente dos métodos tradicionais, causando interesse pessoal por meio de atividades baseadas na vida real, 
mesclando esta interatividade com diversos sentimentos, como humor, drama, alegrias e tristezas.

Outra virtude destacada pela equipe foi o design do Serioues Game, o qual emprega cores, músicas e elementos decorativos variados de forma agradável e que não interferem nos objetivos da aprendizagem. Outro ponto relevado foi o emprego de letras maiúsculas, que ajuda na leitura de crianças ainda em alfabetização e eventos animados com narração sonora, os quais auxiliam a criança em tomadas de decisão ou mesmo a entender os objetivos do jogo sem a necessidade da explicação de um professor.

Finalmente, outro ponto destacado foi quanto a usabilidade de interação com o Jogo Sério, pela sua facilidade de navegação entre as telas e cenários, tornando esta navegação intuitiva e livre. Além da facilidade de navegação, as instruções contidas no jogo são de fácil entendimento, pois utiliza uma linguagem simplificada e inerente aquela que as crianças utilizam no seu dia a dia.

\section{CONSIDERAÇÕES FINAIS}

Os Jogos Sérios oferecem muitas possibilidades, formas de educar e instruir as crianças. Estes jogos estimulam a criança de muitas formas, diferentemente dos métodos tradicionais de ensino, onde a base educacional acontece por meio de giz e do quadro negro.

Batizado de "Joy e as Letrinhas", este Jogo Sério, baseado nas notas da equipe multidisciplinar, pode vir a auxiliar e contribuir com o processo de ensino/aprendizagem, podendo colaborar com o desenvolvimento das habilidades das crianças.

\section{REFERÊNCIAS BIBLIOGRÁFICAS}

ALVAREZ, A. G.; Tecnologia persuasiva na aprendizagem da avaliação da dor aguda em enfermagem. Tese de doutorado - Universidade Federal de Santa Catarina, Centro de Ciências da Saúde, Programa de Pós-Graduação em Enfermagem, Florianópolis, 2014. Disponível em: https://repositorio.ufsc.br/xmlui/handle/123456789/128987. Acesso em 20/08/2017.

ATAIDE, M. E. M.; Contribuições dos jogos em educação. In: XVIII Congresso Internacional de Educação a Distância. Brasília, 2012. Disponível em: http://www.abed.org.br/congresso2012/anais/296c.pdf. Acesso em:12/06/2017.

CARVALHO, C. V.; ANDRÉS, P. M. L.; ARBELOA, F. J. S.; Serious Games Network. Virtual Archaeology Review, v. 4, p. 174-180, 2012. Disponível em: http://romulo.det.uvigo.es/ticai/libros/Ticai_completos/Ticai_2012.pdf. Acesso em: $12 / 06 / 2017$.

DUDEK, C.; COSTA, R. R.; O brincar e a aprendizagem na educação infantil de quatro a seis anos. In: anais do III Congresso Nacional da Área de Educação, 2012. http://www.pucpr.br/eventos/educere/educere2005/anaisEvento/documentos/com/TCCI 118.pdf. Acesso em: 23/05/2017.

GOULD, W. L.; BARKUN, M.; Social science literature: a bibliography for international law. Princeton University Press, 2015. p 83. Disponível em: https:/www.amazon.com/Social-Science-Literature-Bibliography-

International/dp/0691619514. Acesso em: 26/05/2017.

KARLINI, D.; RIGO, S. J.; ABCLINGO: Integrando Jogos Sérios e Mineração de Dados Educacionais no Apoio ao Letramento. Proceedings of SBGames, 1149-1152, 2014. Disponível 
http://www.sbgames.org/sbgames2014/files/papers/culture/short/Cult_Short_2_ABCLin go.pdf. Acesso em: 24/05/2017.

LIMA, M. C. F.; SILVA, V. V. S.; SILVA, M. E. L.; Jogos educativos no âmbito educacional: um estudo sobre o uso de jogos no projeto MAIS da Rede Municipal do Recife. Recife, 2009. Disponível em: http://www.ufpe.br/rtcc. Acesso em: 22/05/2017.

MAGAGNIN, C. D. M.; TOSCHI, M. S.; Aprendizagem escolar: os jogos eletrônicos na formação do aluno, 2009. Disponível em: https://anaisdosimposio.fe.ufg.br/up/248/o/1.4._52_.pdf. Acesso em: 24/05/2017.

MEDEIROS, M. O.; \& SCHIMIGUEL, J.; Uma Abordagem para avaliação de jogos educativos: ênfase no ensino fundamental. In: Brazilian Symposium on Computers in Education, v. 23, n. 1, 2012. Disponível em: http://www.brie.org/pub/index.php/sbie/article/view/1787 Acesso em: 21/08/2017.

MONTEIRO, T. V. B.; MAGAGNIN, C. D. M.; ARAÚJO, C. H. S.; Importância dos Jogos Eletrônicos na Formação do Aluno. Anápolis, 2009. Disponível em: https://anaisdosimposio.fe.ufg.br/up/248/o/Tairine_Vieira_Barros_Monteiro_Cla_dia _Dolores_Martins_Magagnin_e_Cl_udia_Helena_dos_Santos_Ara_jo.pdf. Acesso em: $12 / 0 \overline{6} / 2017$.

NESBIT, J.; BELFER, K.; LEACOCK T.; Learning Object Instrument Review (LORI) - user manual. Version 1.5, 2009. Disponível em: http://www.transplantedgoose.net/gradstudies/educ892/LORI1.5.pdf. Acesso em: 21/08/2017.

OLIVEIRA, R. G. S. G. ; ARAUJO, R. A. F. ; MENEZES, R. S. ; PAIVA, A. C. ; BRAZ, G.; Matematicando: um serious game para o aprendizado da matemática através de uma visão lúdica. In: Anais da V Jornada de Informática do Maranhão. São Luis, 2014. Disponível em: http://sistemas.deinf.ufma.br/anaisjim/artigos/2014/201414.pdf. Acesso em: 26/05/2017.

OLIVEIRA, T. M. V.; Amostragem não probabilística: adequação de situações para uso e limitações de amostras por conveniência, julgamento e quotas. Administração on line, v. 2, n. 3, 2001. Disponível em: http://www.fecap.br/adm_online/art23/tania2.htm. Acesso em: 22/08/2017.

RODRIGUES, H. F.; MACHADO, L.; VALENÇA, A. M. G. Uma proposta de serious game aplicado à educação em saúde bucal. In: anais do Workshop de Realidade Virtual e Aumentada, Santos, 2009. Disponível em: http://www.de.ufpb.br/ labteve/publi/2009_wrva5.pdf. Acesso em: 21/05/2017.

SAVI, R.; ULBRICHT, V. R.; Jogos digitais educacionais: benefícios e desafios. Revista RENOTE, v. 6, n. 2, 2008. Disponível em: http://seer.ufrgs.br/renote/article/view/14405. Acesso em: 24/05/2017.

SILVA, I. K. O.; MORAIS, M. J. O.; Desenvolvimento de jogos educacionais no apoio do processo de ensino-aprendizagem no ensino fundamental. Revista HOLOS, v. 5, p. 153-164, 2011. Disponível em: http://www2.ifrn.edu.br/ojs/index.php/HOLOS/article/view/705. Acesso em: $11 / 06 / 2017$.

SILVA, J. P. C.; Metodologias e meios mais utilizados na alfabetização entre os profissionais da educação. Aripuanã, 2011. Disponível em: http://www.biblioteca.ajes.edu.br/arquivos/monografia_20130423162431.pdf. Acesso em: 23/05/2017.

SOUZA, A. F.; Alfabetização e o lúdico, a importância dos jogos na educação fundamental. Centro Universitário Católico Salesiano Auxilium, Lins, 2013. Disponível em: http:/www.unisalesiano.edu.br/biblioteca/monografias/55997.pdf. Acesso em: 24/05/2017. 